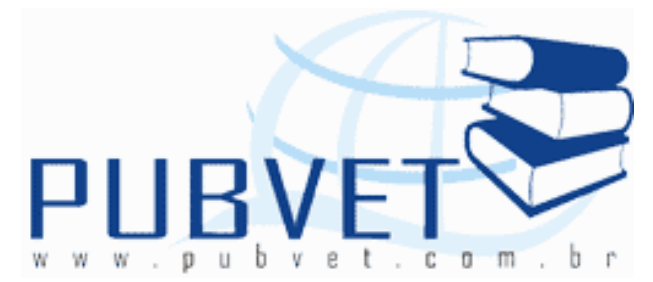

PUBVET, Publicações em Medicina Veterinária e Zootecnia.

\title{
Associação entre o mérito genético e o desempenho a pasto de bovinos da raça Nelore
}

\author{
Graniele Rodrigues da Cruz ${ }^{1}$; Rodrigo Zaiden Taveira²; Osvaldo José da Silveira \\ Neto²; Cintia Roberta Neves Tosta ${ }^{3}$; Júlia de Miranda Moraes ${ }^{3}$ \\ ${ }^{1}$ Acadêmica do curso de Zootecnia.UEG - São Luís de Montes Belos, GO. \\ ${ }^{2}$ Docente e pesquisador - Curso de Zootecnia -UniversidadeEstadual de Goiás - \\ UEG -Rua da Saudade, no 56, Vila Eduarda,São Luís de Montes Belos, GO. \\ ${ }^{3}$ Docente e pesquisadora - Curso de Medicina Veterinária - Faculdades \\ Objetivo- ASSOBES-IUESO - Goiânia, GO.
}

\section{Resumo}

Objetivou-se verificar o nível de associação entre o desempenho de novilhos da raça Nelore participantes da prova de ganho em peso a pasto com a DEP 450 dias e mérito genético total (MGT) de seus pais. Os dados utilizados no presente estudo foram provenientes de animais da raça Nelore, categoria Puro de Origem (PO), criados na Agropecuária Camargo localizada no município de Araguapaz, GO. A prova teve duração de 294 dias, tendo sido 70 dias de adaptação e 224 dias de prova propriamente dita. Foram avaliados todos nas mesmas condições de criação, grupo de manejo e regime alimentar. Houve acréscimo médio de $107 \mathrm{~kg}$ do peso inicial para o peso no final da prova, indicando ganho médio diário de $0,36 \mathrm{~kg} / \mathrm{dia}$. Pode ser constatado que a categoria superior foi a possuidora da maior porcentagem de animais 
CRUZ, G.R. et al. Associação entre o mérito genético e o desempenho a pasto de bovinos da raça Nelore. PUBVET, Londrina, V. 8, N. 14, Ed. 263, Art. 1748, Julho, 2014.

classificados $(40,91 \%)$. Houve acréscimo nas estimativas das correlações simples da DEP 450 dos touros com o peso inicial $(0,12)$ e peso final de suas progênies $(0,35)$. A associação positiva entre o desempenho ponderal das progênies com a DEP 450 dias e MGT dos touros, evidenciam que estas ferramentas encontram-se adequadas para a seleção de reprodutores.

Palavras-chave: ganho em peso, melhoramento genético, zebuínos.

\section{Genetic merit and pasture performance association in Nellore bovines}

\section{Abstract}

The aim was to verify the association level between the steers performance of Nellore breed evaluate in weight gain test on pasture with the DEP 450 days and total genetic merit of theirs fathers. The data used in this study was from Nellore animal, in pure blood, form Camargo farm, located in the Araguapaz city, Goiás state. The test showed duration of 294 days, being 70 days of adaptation and 224 days of test. All of animals were evaluated in the same conditions of handling and alimentation. There was average increase of 107 $\mathrm{Kg}$ from initial to final weight, showing daily average gain of $0.36 \mathrm{~kg} / \mathrm{day}$. Can be detected that the superior category showed the highest percentage of classified animals (40.91\%). There was increase in the simple correlation estimative of DEP 450 days of bulls with initial weight (0.12) and final weight (0.35) of their offspring. The positive association between the weight performance of offspring with DEP 450 days and total genetic merit of bulls shows that these tools are necessary for the bulls' selection.

Keywords: genetic improvement, weight gain, zebuines.

\section{Introdução}

A economia globalizada dos últimos tempos levou a pecuária de corte a uma situação onde apenas criadores atualizados se destacarão no competitivo mercado. Todos aqueles que não atingirem níveis adequados de qualidade e 
CRUZ, G.R. et al. Associação entre o mérito genético e o desempenho a pasto de bovinos da raça Nelore. PUBVET, Londrina, V. 8, N. 14, Ed. 263, Art. 1748, Julho, 2014.

produtividade serão marginalizados do processo produtivo, podendo até ser eliminados do mesmo ou mudar o ramo da atividade. As palavras de ordem dos tempos atuais consistem em aumentar a produtividade e melhorar a qualidadedos produtos, sempre a custos minimizados (FERRAZ \& ELER, 2012).

A tarefa de melhorar a produtividade da pecuária de corte de forma eficiente e sustentável requer ações integradas e holísticas em todos os componentes do sistema de produção. A aplicação de novas tecnologias deve ser integrada com as questões de manejo, ambiente e genética animal. A seleção e o uso de animais geneticamente superiores permitem racionalização entre o ganho individual e produtividade por hectare aumentando a rentabilidade do sistema. Porém, esses benefícios são dependentes de condições de ambiente adequadas, que permitam a expressão do potencial genético dos animais (LÔBO \& FARIA, 2008).

Considerando que mais de $90 \%$ dos reprodutores utilizados no Brasil são ativamente trabalhados em monta natural, percebe-se, portanto, a importância de se proceder à seleção genética eficiente desses animais (CHAGAS, 2006). Em virtude dessa realidade aProva de Ganho de Peso (PGP)aparece como um instrumento valioso na identificação dos reprodutores de melhor valor genético para terem suas progênies criadas a pasto, coincidindo com a realidade da maioria das propriedades nacionais.

A PGP a pasto auxilia na identificação entre os participantes aqueles de melhor desempenho no peso final padronizado aos 550 dias de idade, identificando aqueles animais de melhor ganho em peso diário, fornecendo subsídios para a sua seleção, com base na informação individual. Com isso, tem-se a possibilidade de identificar quais os reprodutores que transmitem às suas progênies, maiores ganhos, em ambiente de manejo a pasto, além de maiorpeso final à idade considerada $(A B C Z, 2012)$.

As informações coletadas nas $\mathrm{PGP}_{\mathrm{s}}$ integrarão 0 banco de dados referentes à análise genética dos touros, culminando em índices ponderados que expressam o mérito genético total (MGT) de um animal para as várias características de interesse, quando o mesmo é utilizado na reprodução. 
O MGT do Programa de Melhoramento Genético da Raça Nelore reúne num único índice informação referente às diferentes predições do valor genético de cinco características. O cálculo leva em conta a DiferençaEsperada na Progênie (DEP) para: efeito materno do peso aos 120 dias de idade, efeito genético direto para peso aos 120; 365 e 450 dias de idade e perímetros escrotais aos 365 e 450 dias de idade, podendo ser utilizado para selecionar animais com as características desejadas (GARNEIRO et al. 2006).

Considerando todo o exposto, objetivou-se verificar o nível de associação do desempenho de novilhos da raça Nelore participantes de PGP com a DEP 450 dias e MGTde seus pais.

\section{Material e Métodos}

Os dados utilizados no presente estudo foram provenientes do plantel bovino da raça Nelore, localizado em propriedade agropecuária no município de Araguapaz, região noroeste do estado de Goiás, caracterizada por clima tropical úmido e com temperatura média de $22^{\circ} \mathrm{C}$.

Participaram da PGP 44 novilhos da raça Nelore, com idade média de 08 meses de idade, todos possuidores de registro genealógico de nascimento (RGN). Os animais foram manejados no sistema de pastejo extensivo, em pastagens do gênero BrachiariabrizanthacvMarandu, em sistema rotacionado no qual o período de pastejo e descanso são definidos pela disponibilidade de forrageira.

A prova teve duração de 294 dias, tendo sido 70 dias de adaptação e 224 dias de prova propriamente dita. Foram avaliados todos nas mesmas condições de criação, grupo de manejo e regime alimentar.

A mineralização era fornecida ad libidum, em cochos apropriados respeitando a relação linear de $20 \mathrm{~cm} /$ cabeça. O mineral fornecido aos animais continha seus níveis de garantias de acordo com a categoria animal. A água foi fornecida ad libidum, por meio de bebedouros apropriados, sendo proveniente 
CRUZ, G.R. et al. Associação entre o mérito genético e o desempenho a pasto de bovinos da raça Nelore. PUBVET, Londrina, V. 8, N. 14, Ed. 263, Art. 1748, Julho, 2014.

de poço artesiano. A limpeza destes bebedouros ocorria a cada 05 dias, preservando-se a qualidade da água fornecida.

Todos os manejos foram realizados visando o bem estar animal e a maximização da produção, proporcionando condições favoráveis e condizentes com a realidade da pecuária nacional, possibilitando ao animal a expressão de seu fenótipo em decorrência do seu potencial genético.

As pesagens realizadas foram: Pré-adaptação, ocorrida na entrada dos animais na prova; Inicial, ocorrida 70 dias após o início da prova, a qual marca o início propriamente dito da prova, e mais três pesagens com intervalos de 56 dias. A pesagem final ocorreu após 294 dias de prova, contando o período de adaptação. Todas as pesagens foram realizadas com o animal em jejum alimentar por período de doze horas.

Com as informações dos pesos registrados foram calculados os ganhos em peso (GP), o ganho médio diário aos 224 dias (GMD224) e o peso calculado aos 550 dias de idade (PC 550). Estes índices compuseram o índice da prova de ganho em peso (IPGP).

$\mathrm{Na}$ ocasião da última pesagem, foram realizadas as avaliações visuais para as seguintes características: Estrutura corporal, Precocidade, Musculatura, Umbigo, Racial, Aprumos e Sexual, pelo método EPMURAS. A pontuação desta avaliação também é determinante, pois, possui peso no IPGP de $20 \%$, o qual classifica o animal em: Elite, Superior, Regular, Inferior ao final de todas as avaliações.

\section{Resultados e Discussão}

A Tabela 1 registra os valores mínimos, médios, máximos e coeficiente de variação (\%) do peso inicial e peso final da progênie de touros da raça Nelore submetidos à prova de ganho em peso a pasto. 
CRUZ, G.R. et al. Associação entre o mérito genético e o desempenho a pasto de bovinos da raça Nelore. PUBVET, Londrina, V. 8, N. 14, Ed. 263, Art. 1748, Julho, 2014.

Tabela 1. Valores mínimos, médios, máximos e coeficientes de variação (\%) do peso inicial e peso final da progênie de novilhos da raça Nelore submetidos à prova de ganho em peso à pasto em propriedade rural localizada no município de Araguapaz, GO.

\begin{tabular}{ccccc}
\hline Características & Mínimo $(\mathrm{kg})$ & $\begin{array}{c}\text { Média } \pm \mathrm{DP} \\
(\mathrm{Kg})\end{array}$ & $\begin{array}{c}\text { Máximo } \\
(\mathrm{Kg})\end{array}$ & $\begin{array}{c}\mathrm{CV} \\
(\%)\end{array}$ \\
\hline Peso Inicial & 160 & $207,61 \pm 22,17$ & 267 & 10,67 \\
& & & & \\
Peso Final & 267 & $340,11 \pm 28,52$ & 400 & 8,38 \\
& & & & \\
\hline
\end{tabular}

Tendo em vista o desempenho da progênie submetida aPGP a pasto, foi observado que houve acréscimo médio de $107 \mathrm{~kg}$ do peso inicial para o peso no final da prova, indicando ganho médio diário de 0,36 kg/dia. Esse ganho encontra-se inferior aos $0,45 \mathrm{~kg} / \mathrm{dia}$ registrados porMUNIZ et al. (2008)avaliando o desempenho de animais da raça Nelore à pasto com suplementação mineral proteico-energético durante o período da seca. Esse ganho adicional pode ser atribuído, em parte, ao uso de suplementação para os animais, o que não aconteceu no presente estudo. Os autores acrescentam ainda que esse GMD só foi possível devido à disponibilidade de massa seca oriunda do sistema de integração lavoura e pecuária associada à suplementação proteico-energética a qual os animais receberam como alimentação.

A diferença em peso do animal mais leve para o animal mais pesado do lote foi de $133 \mathrm{~kg}$, evidenciando o efeito aleatório dos genes sobre as variáveis estudadas, já que as características de meio encontravam-se padronizadas.

Os coeficientes de variação encontrados nesse trabalho apresentam-se de baixa magnitude, indicando influência controlada dos fatores de meio sobre os dados de desempenho animal. 
CRUZ, G.R. et al. Associação entre o mérito genético e o desempenho a pasto de bovinos da raça Nelore. PUBVET, Londrina, V. 8, N. 14, Ed. 263, Art. 1748, Julho, 2014.

A Tabela 2apresenta a classificação das progênies dos touros ao final da PGP à pasto considerando as categorias de elite, superior, regular e inferior.

Tabela 2. Classificação das progênies dos touros ao final da prova de ganho em peso a pasto considerando as categorias de elite, superior, regular e inferior realizada em propriedade rural localizada no município de Araguapaz, GO.

\begin{tabular}{llc}
\hline Categoria & $\mathrm{N}$ & $\mathbf{\%}$ \\
\hline Elite & 05 & 11,36 \\
Superior & 18 & 40,91 \\
Regular & 16 & 36,36 \\
Inferior & 05 & 11,36 \\
\hline Total & 44 & 100 \\
\hline
\end{tabular}

Pode ser constatado que a categoria superior foi a possuidora da maior porcentagem de animais classificados (40,91\%). As categorias elite e inferior obtiveram a mesma quantidade de animais pontuando $(11,36 \%)$, ficando grande parte dos animais $(77,27 \%)$ ranqueados entre as categorias superior e regular.

Na Tabela 3 podem ser observados as estimativas de correlações simples da DEP 450 de touros da raça Nelore com o peso inicial e peso final de suas progênies.

Pode ser constatado que houve acréscimo nas estimativas das correlações fenotípicas da DEP 450 dos touros com o peso inicial $(0,12)$ e peso final de suas progênies $(0,35)$. Esses resultados indicam haver associação positivas entre as características estudadas, já que os touros possuidores de maiores DEP 450 tenderam a apresentar filho com maiores pesos inicial e final, com destaque para esse último.

Acrescenta-se, entretanto, que a seleção não deve ser baseada somente no peso absoluto do animal, sob o risco de haver retardamento das 
CRUZ, G.R. et al. Associação entre o mérito genético e o desempenho a pasto de bovinos da raça Nelore. PUBVET, Londrina, V. 8, N. 14, Ed. 263, Art. 1748, Julho, 2014.

precocidades sexual, crescimento e terminação, o que tornaria oneroso os sistemas de produção.

Tabela 3. Correlações simples da DEP 450 de touros da raça Nelore com o peso inicial e peso final de suas progênies submetidas à prova de ganho em peso a pasto e intervalo de confiança (95\%) dos dados, em experimento conduzidoem propriedade rural localizada no município de Araguapaz, GO.

Características $\quad$ Peso Inicial Peso Final

$\begin{array}{lll}\text { DEP } 450 & 0,12 & 0,35\end{array}$

IC $(95 \%) \quad-0,1802-0,4055 \quad 0,0686-0,5922$

O valor econômico de um animal como reprodutor não é determinado por uma característica isolada, mas sim, pelo conjunto das características de maior interesse econômico, para as quais ele transmite genes para a sua progênie.

A avaliação genética fornece predições do valor genético (DEP) do animal para cada uma destas características. As decisões de seleção devem ser baseadas em cada uma destas informações, tarefa que se torna bem mais simples com a utilização de um índice que reúna em um único valor as várias predições, procurando ponderá-las da forma mais adequada para a maximização do progresso genético e, como consequência, da produtividade. Nesse sentido, utiliza-se o MGT dos touros, como sendo um índice ponderado que harmonicamente equilibra as características julgadas mais importantes dentro de um programa de melhoramento.

A Tabela 4 apresenta as estimativas de correlações simples do MGT de touros da raça Nelore com o peso inicial e peso final de suas progênies e intervalo de confiança dos dados (95\%). 
CRUZ, G.R. et al. Associação entre o mérito genético e o desempenho a pasto de bovinos da raça Nelore. PUBVET, Londrina, V. 8, N. 14, Ed. 263, Art. 1748, Julho, 2014.

Tabela 4. Estimativas de correlações simples do MGT de touros da raça Nelore com o peso inicial e peso final de suas progênies submetidas à prova de ganho em peso a pasto e intervalo de confiança (95\%) dos dados,em experimento realizado em propriedade rural localizada no município de Araguapaz, GO.

\begin{tabular}{lcc}
\hline \multicolumn{1}{c}{ Características } & Peso Inicial & Peso Final \\
\hline MGT & 0,03 & 0,33 \\
IC $(95 \%)$ & $-0,2615$ & $0,04196-0,5746$ \\
\hline
\end{tabular}

Pode ser constatado que houve associação positiva entre o MGT dos touros avaliados com os pesos inicial e final de suas progênies, indicando que os animais possuidores de maior MGT produziram filhos mais pesados, tanto no início quanto no final da prova, sendo esta associação mais evidente na pesagem final. Esse resultado se explica também, em parte, pela ponderação do MGT levar em conta informações sobre o ponderal dos animais.

A tabela 5 apresenta a estimativa da correlação fenotípica da DEP 450 de touros da raça Nelore com a colocação final de suas progênies submetidas à PGP a pasto.

Tabela 5. Estimativa de correlação da DEP 450 de touros da raça Nelore com a colocação final de suas progênies submetidas à prova de ganho em peso a pasto e intervalo de confiança (95\%) dos dados, em experimento conduzido em propriedade rural localizada no município de Araguapaz, GO.

\begin{tabular}{lc}
\hline Características & Colocação da Progênie \\
\hline DEP 450 & $-0,4128$ \\
IC $(95 \%)$ & $(-0,6322$ a $-0,1320)$ \\
\hline
\end{tabular}


CRUZ, G.R. et al. Associação entre o mérito genético e o desempenho a pasto de bovinos da raça Nelore. PUBVET, Londrina, V. 8, N. 14, Ed. 263, Art. 1748, Julho, 2014.

Pode ser registrada associação negativa e de moderada magnitude entre a DEP 450 dos touros com a colocação final de suas progênies, indicando que touros possuidores de maiores DEP 450 produziram progênies com menor colocação na pontuação final, o que nesse caso quer dizer melhor resultado.

\section{Conclusão}

A associação positiva entre o desempenho ponderal das progênies com a DEP 450 dias e MGT dos touros, evidencia que estas ferramentas encontramse adequadas para a seleção de reprodutores com o papel de produzir progênies selecionáveis pelo desempenho.

\section{Referências Bibliográficas}

ABCZ. Manual do PGP. Disponível em: http://www.pmgz.org.br/?pgpManual. Acessado em: 04 de Maio de 2012.

CHAGAS, B. B. Prova de ganho em peso com destaque para Raça Tabapuã confinamento oficializado pela ABCZ. 2006. 29 f. Especialização(Zootecnia). FAZU. Copacabana - RJ. 2006.

FERRAZ, J. B. S.; ELER, J. P. Seleção de zebuínos para características produtivas. I Simpósio de Produção de Gado de Corte. Grupo de Melhoramento Animal. Universidade de São Paulo - Faculdade de Zootecnia e Engenharia de Alimentos. Pirassununga - SP. 22p. 2012.

GARNEIRO, A. V. et al.A genealogia e sua influência no valor genético de reprodutores da raça Nelore. Revista Ciência Agronômica, v.37, n.2, p.235-240, Centro de Ciências Agrárias - Universidade Federal do Ceará, Fortaleza, CE, 2006.

LÔBO, R. B.; FARIA, C. U. Princípios e resultados de pesquisas científicas do programa de Nelore Brasil. AssociaçãoNacional de criadores e pesquisadores. Ribeirão Preto - SP. 360 P. 2008.

MUNIZ, L. C. et al. Avaliação econômica de duas estratégias de recria de bovinos Nelores utilizando pastagens renovadas em sistema de integração lavoura e pecuária. $\square$ x Simpósio nacional cerrado - Desafios e estratégias para o equilíbrio entre sociedade, agronegócio e recursos naturais. Brasília - DF. 2008. 